\title{
Determinants of preterm infants' deaths at the Neonatal Intensive Care Units in the Northeast Countryside in Brazil
}

Raquel Gomes Lima 1

https://orcid.org/0000-0001-5344-3508

Verônica Cheles Vieira 2

iD https://orcid.org/0000-0001-6395-4096

Danielle Souto de Medeiros 3

https://orcid.org/0000-0002-2480-8990

1-3 Instituto Multidisciplinar em Saúde. Universidade Federal da Bahia. Campus Anísio Teixeira. Rua Hormindo Barros, 58. Quadra 17, Lote 58. Bairro Candeias. Vitória da Conquista, BA, Brasil. CEP: 45.029-094. E-mail: rcglima@gmail.com

\begin{abstract}
Objectives: to assess preterm infants' characteristics, health conditions and neonatal care effect on their death at the neonatal ICU.

Methods: this was a non-concurrent cohort study, including preterm infants from three neonatal ICUs from January 1st to December 31st, 2016, followed during the neonatal period and deaths registered during the entire hospitalization. Multivariate analysis was performed using Poisson regression.

Results: of the 181 preterm infants, $18.8 \%$ died during hospitalization. Associated with the outcome: a gestational age between 28 and 32 weeks $(R R=5.66 ; C 195 \%=2.08-15.40)$, and less than 28 weeks $(R R=9.24 ; C 195 \%=3.27-26.12)$, Apgar score of 5th minutes less than 7 (RR: 1.82; $C 195 \%=1.08-3.08)$, use of invasive mechanical ventilation up to 3 days $(R R=$ 4.44; $C 195 \%=1.66-11.87)$ and 4 days and more $(R R=6.87$; $C 195 \%=2.58-18.27)$. Besides the late sepsis (RR: 3.72, CI95\%=1.77-7.83), acute respiratory distress syndrome $(R R=2.86$, $C I 95 \%=1.49-5.46)$, pulmonary hemorrhage $(R R=1.97 ; C I 95 \%=1.40-2.77)$, and necrotizing enterocolitis $(R R=3.41 ; C 195 \%=1.70-6.83)$.

Conclusions: the results suggest the importance of using strategies to improve care during childbirth, conditions for extremely premature infants, early weaning from a mechanical ventilation and prevention on nosocomial infection.
\end{abstract}

Key words Premature newborn, Death, Neonatal ICU, Longitudinal studies 


\section{Introduction}

Prematurity constitutes as an important public health priority worldwide 1 and its complications were responsible for $18 \%$ of the mortality in children under 5 years old in 2016.2 In Brazil, França et al. ${ }^{3}$ research highlighted prematurity as the main cause of death in children below 5 years old, in the States of Acre and Bahia were the ones with the highest rates.

The maintenance of these indicators suggests failure in the obstetric and neonatal care, accompanied by national and regional inequalities care, quality at the neonatal intensive care unit (ICU), healthcare provided, and disproportional distribution of beds at the neonatal ICU,4 with greater inequalities in towns in the countryside and especially those more distant from the cities.

The preterm infants' survival depends on various factors, highlighting on the higher risk of mortality of those small for gestational age, gestational age (GA) of $<28$ weeks, in need of resuscitation maneuvers in the delivery room, and low Apgar score at the 5th min.5-7 Prematurity complications conceded this group with the highest death rates when compared to those born at term and they were divided into short and long-term complications. ${ }^{8}$ Studies on this population show that pulmonary hemorrhage, respiratory distress syndrome, and necrotizing enterocolitis are some of the main short-term morbidities that interfere in the preterm infants' death.5-7,9

With the evolution of multi-professional care at the neonatal ICU, knowledge is required when it comes to the conditions experienced by preterm infants that interfere with their mortality and survival. This knowledge reflects on human and technological resources that permeate in this care. Factors associated with preterm infants' mortality and survival reflect on the entire journey of this fragile baby from the maternal uterus until his/her long stay at the neonatal ICU. Thus, this present research aimed to assess the newborns' characteristics effects, health conditions, and neonatal care on preterm infants' deaths hospitalized at the neonatal ICU in a town in the Northeast Brazilian countryside.

\section{Methods}

This is a non-concurrent cohort study, hospitalbased, that included preterm infants admitted at three neonatal ICU in a mid-sized town located in the Northeast Brazilian countryside, located more than $500 \mathrm{~km}$ from the capital of the State and with approximately 2 million dependents of its health services. This town has a Índice de Desenvolvimento Humano Municipal (IDHM) (City Human Development Index) of 0.678 in 2010 (average range in the IDHM). Longevity was the domain that mostly contributed with the IDHM, followed by income and education. Its per capita income in 2010 was $\mathrm{R} \$ 555.66 .10$

All the preterm infants that were admitted to the neonatal ICU from January $1^{\text {st }}$ to December $31^{\text {st }}$, 2016, were included. The population was followed from the day of admission until hospital discharge, transference, or death, following the censorship of 27 days of life (follow-up interruption). Those with any major congenital anomaly were excluded from this study, such as severe anatomical alterations: complex congenital heart diseases, gastrointestinal tract atresia, abdominal wall defects, hydrocephalus, encephalocele, and diaphragmatic hernia.

Data were obtained by analyzing medical and statistical records stored in three hospitals that assist the population in urban and rural areas. Two of these neonatal ICU are located in the public administration hospitals: only one is a public reference for high-risk pregnancies in the region and the other does not perform obstetric procedures, and assisting referred patients from other institutions with maternity wards. The third ICU is located at a private funded hospital. Each neonatal ICU offers 10 beds and serves as an internship field for the pediatric and neonatology medical residences, thus these clinical practice protocols are very similar.

The Human Research Ethics Committee of the Instituto Multidisciplinar em Saúde da Universidade Federal da Bahia (UFBA) (Multidisciplinary Health Institute of the Federal University of Bahia) (CAAE: 79450717.4.0000.5556 and document number 2.485.073) approved this study on February 5th, 2018 .

The total number of eligible preterm infants' medical records were used to estimate the minimum sample size in $2016(\mathrm{~N}=248)$. The following parameters were applied: expected frequency of $50 \%$, given to the heterogeneity of the outcomes, the accuracy was measured at $5 \%$, confidence interval of $95 \%$, and an increase of $20 \%$ for possible losses, resulting in 181 medical records.

Data were collected by volunteer health researchers after training and under the supervision of neonatologists using a specific questionnaire, based on the Inquérito Nascer para o Brasil (Born for Brazil Survey) instrument.11 A pilot study was conducted in May 2018, with approximately $20 \%$ of the total number of medical records, from November 
to December 2015 for the three neonatal ICU, thus, the objective of the pilot study was to improve and standardize the instrument and enable researchers to collect data. The data collection took place from June to October 2018, using tablets containing a digital questionnaire created using the Kobo Toolbox 1.4.8 ${ }^{\circledR}$ application.

The dependent variable was death during the hospitalization period at the neonatal ICU.

The independent variables used were divided into two blocks: the first block containing the newborn's characteristics, health conditions, and neonatal care. The gestational age was obtained using the best obstetric estimate, a reference by the date of the last menstruation, followed by early ultrasonography. Due to the impossibility of these findings, the evaluation of physical and neurological signs of newborns was used.12,13 The gestational age was estimated in weeks and categorized according to the World Health Organization as extreme preterm (less than 28 weeks), very preterm ( 28 to less than 32 weeks), and moderate/late preterm (32 to less than 37 weeks). ${ }^{1}$ Birth weight was measured in grams and classified as adequate/low weight $(>1,500$ $\mathrm{g}$ ), very low weight (between 1,000 and 1,500 g), and extremely low weight $(<1,000 \mathrm{~g})$.

The other variables used were Apgar score at the 5th minute of life (Apgar $<7$ and $\geq 7$ ); resuscitation procedures in the delivery room (not needed, positive pressure ventilation [PPV] or advanced resuscitation: PPV accompanied by cardiac massage and/or drugs); 14 use of early continuous positive pressure (CPAP) in the delivery room (yes or no); use of surfactant in the delivery room and/or neonatal ICU (yes or no); use of invasive mechanical ventilation during the neonatal period $(0,1-3$, or 4 days and more); and use of central venous access (up to 6 or 7 and more days). The categorization of variables use of mechanical ventilation and central venous access - was performed by using the medians.

The second block presented the newborn's clinical evolution in the neonatal period: acute respiratory distress syndrome, early sepsis, late sepsis (received antibiotic scheme for late sepsis and/or report on the diagnosis described in the medical record), pulmonary hemorrhage, and necrotizing enterocolitis (all categorized as yes or no).

To describe the assessed population's characteristics, the following variables were also used: sex (male or female), maternal race/color (white or black/mixed), maternal age $(<20 ; 20-34 ; \geq 35$ years old);15,16 marital status (with a partner and without a partner), maternal schooling (without schooling/elementary; high school or higher educa- tion), and place of residence (rural or urban area).

Losses were evaluated by comparing the obtained sample with the total population using Pearson's chi-square test or linear trend and showed no differential losses according to the analyzed variables (hospital of origin and weight at birth). Nevertheless, to assess whether there would be or not an impact on the death outcome, a calibration of natural expansion factors was performed. These factors consisted of estimating weights for each element of the sample, according to the variable information for the total population. ${ }^{17}$ When comparing the estimates on the relative risk points on deaths with and without the calibration factor, no significant differences were observed in the estimates $(p=0.26)$, and thus, the analyses were conducted without considering the calibration factor. The descriptive analysis of these variables was carried out using absolute and relative frequencies. The bivariate analysis between independent variables and death was made by Poisson's regression with robust variance, obtaining estimates on relative risk (RR) and its respective $95 \%$ confidence interval (CI95\%). Differences between exposures of interest and the outcome occurrence were tested using Pearson's chi-square or Fisher's exact tests. For the multivariate analysis, the Stepwise Backward method was adopted, which consists of inserting all explanatory variables of the proposed model and then removing them in stages. All variables that presented an association with the outcome at a significance level of $<20 \%$ were included in the initial model in the bivariate analysis. For all tests and variable permanence in the final model, a significance level of $<5 \%$ was used. These models were compared using Akaike's criterion and the adequacy was evaluated by the chi-square test. The Stata program version 15.0 (Stata Corporation, College Station, USA) was used for analysis.

\section{Results}

A total of 265 preterm infants were admitted to the units during the study period, 17 were excluded because of some major congenital malformation, and 67 medical records were not found, having a sample of 181 preterm infants. Among them, 59.7\% were males, with mothers aged between 20 and 34 years old $(66.3 \%)$, black/mixed color $(62.4 \%)$, living without a partner $(42.5 \%)$, with high school education $(29.3 \%)$ and residents of urban area $(79.6 \%)$ (Table 1).

Of the studied population, $18.8 \%$ (34) preterm infants died during their stay at the neonatal ICU, 
Table 1

\begin{tabular}{|c|c|c|}
\hline Variables & $\mathbf{N}$ & $\%$ \\
\hline \multicolumn{3}{|l|}{ Sex } \\
\hline Male & 108 & 59.7 \\
\hline Female & 73 & 40.3 \\
\hline \multicolumn{3}{|l|}{ Maternal age (years) } \\
\hline$<20$ & 24 & 13.3 \\
\hline $20-34$ & 120 & 66.3 \\
\hline$\geq 35$ & 35 & 19.3 \\
\hline Ignored & 2 & 1.1 \\
\hline \multicolumn{3}{|l|}{ Maternal race/color } \\
\hline White & 34 & 18.8 \\
\hline Black/Mixed & 113 & 62.4 \\
\hline Ignored & 34 & 18.8 \\
\hline \multicolumn{3}{|l|}{ Marital status } \\
\hline With a partner & 65 & 35.9 \\
\hline Without a partner & 77 & 42.5 \\
\hline Ignored & 39 & 21.6 \\
\hline \multicolumn{3}{|l|}{ Schooling } \\
\hline Without schooling/elementary & 37 & 20.4 \\
\hline High school & 53 & 29.3 \\
\hline Higher education & 47 & 26.0 \\
\hline Ignored & 44 & 24.3 \\
\hline \multicolumn{3}{|l|}{ Place of residence } \\
\hline Rural area & 36 & 19.9 \\
\hline Urban area & 144 & 79.6 \\
\hline Ignored & 1 & 0.6 \\
\hline
\end{tabular}

and $52.9 \%$ of these deaths occurred during the first 7 days of hospitalization. Among the main causes of death were septic shock, multiple organ failure, and acute renal failure.

Gestational age ranged from $230 / 7$ to 36 weeks $6 / 7$, with $62.4 \%$ moderate or late preterm infants, $25.4 \%$ very preterm, and $12.2 \%$ extreme preterm. More than half of the population weighed more than $1,500 \mathrm{~g}(60.2 \%)$, Apgar score at the $5^{\text {th }}$ minute of life $\geq 7(61.3 \%)$, did not require resuscitation maneuvers (58.6\%) or early CPAP in the delivery room $(83.4 \%)$ and $65.8 \%$ did not receive surfactant in the delivery room and/or at the neonatal ICU. The use of central venous access for $<6$ days was observed in $63.0 \%$ of preterm infants and $57.5 \%$ did not receive invasive mechanical ventilation (Table 2). In the neonatal period, $72.4 \%$ of the preterm infants presented early sepsis, $35.4 \%$ late sepsis, $32.0 \%$ respiratory distress syndrome, $1.1 \%$ pulmonary hemorrhage, and $2.8 \%$ necrotizing enterocolitis (Table 3 ).

Bivariate analysis showed a higher risk of death among preterm infants with lower GA, lower weight, with Apgar score at the 5 th minute of life $<7$, who needed advanced resuscitation, who used surfactant in the delivery room and/or at the neonatal ICU, with use of $\geq 7$ days of central venous access and a higher number of days of invasive mechanical ventilation. After the adjustment, gestational age, Apgar score at the 5 th minute $<7$, and a longer time of invasive mechanical ventilation (with dose-response relationship) remained associated with the occurrence of death (Table 2). Additionally, a clinical association was observed with the following diagnoses: late sepsis, acute respiratory distress syndrome, pulmonary hemorrhage, and necrotizing enterocolitis (Table 3).

\section{Discussion}

This is the first study conducted in the region portraying conditions associated with hospitalized preterm infants' death at the neonatal ICU and this serves as a baseline for future follow-ups regarding preterm infants' survival. Approximately $18.8 \%$ of the preterm infants died and most of them occurred with the most immature preterm infants with lower 
Table 2

Description of the studied population according to the newborns' characteristics, health conditions, and neonatal care ( $\mathrm{N}=181)$, incidence, and relative risk for death. Preterm Birth Cohort, 2016.

\begin{tabular}{|c|c|c|c|c|c|c|c|c|}
\hline \multirow[t]{2}{*}{ Variables } & \multirow[t]{2}{*}{ N } & \multirow[t]{2}{*}{$\%$} & \multicolumn{5}{|c|}{ Death } & \multirow[b]{2}{*}{$\mathrm{Cl} 95 \%$} \\
\hline & & & $\mathrm{n}$ & $\%$ & $\mathrm{RR}_{\text {Crude }}$ & $\mathrm{Cl} 95 \%$ & $\mathrm{RR}_{\text {Adjusted }}$ & \\
\hline \multicolumn{9}{|l|}{ Gestational age } \\
\hline Moderate/late preterm & 113 & 62.4 & 5 & 4.4 & 1.00 & - & 1.00 & - \\
\hline Very preterm & 46 & 25.4 & 16 & 34.8 & 7.86 & $3.05-20.25$ & 4.44 & $1.66-11.87$ \\
\hline Extremely preterm & 22 & 12.2 & 13 & 59.1 & 13.35 & $5.28-33.75$ & 6.87 & $2.58-18.27$ \\
\hline \multicolumn{9}{|l|}{ Birth weight } \\
\hline Adequate /low weight & 109 & 60.2 & 5 & 4.6 & 1.00 & - & - & - \\
\hline Very low weight & 47 & 26.0 & 12 & 25.5 & 5.56 & $2.07-14.95$ & - & - \\
\hline Extremely low weight & 25 & 13.8 & 17 & 68.0 & 14.82 & $6.02-36.45$ & - & - \\
\hline \multicolumn{9}{|l|}{ Apgar at the $5^{\text {th }}$ minute of life } \\
\hline$<7$ & 70 & 38.7 & 25 & 34.7 & 4.14 & $2.18-8.89$ & 1.82 & $1.08-3.08$ \\
\hline$\geq 7$ & 111 & 61.3 & 9 & 8.1 & 1.00 & - & 1.00 & - \\
\hline \multicolumn{9}{|l|}{ Resuscitation procedures } \\
\hline None & 106 & 58.6 & 12 & 11.3 & 1.00 & - & - & - \\
\hline Positive pressure ventilation & 57 & 31.5 & 12 & 21.1 & 1.85 & $0.89-3.87$ & - & - \\
\hline Advanced resuscitation* & 18 & 9.9 & 10 & 55.6 & 4.90 & $2.49-9.64$ & - & - \\
\hline \multicolumn{9}{|l|}{ Early CPAP in the delivery room } \\
\hline No & 151 & 83.4 & 28 & 18.5 & 1.00 & - & - & - \\
\hline Yes & 30 & 16.6 & 6 & 20.0 & 1.07 & $0.48-2.38$ & - & - \\
\hline \multicolumn{9}{|l|}{ Use of surfactant } \\
\hline No & 119 & 65.8 & 13 & 10.9 & 1.00 & - & - & - \\
\hline Yes & 62 & 34.2 & 21 & 33.9 & 3.10 & $1.66-5.77$ & - & - \\
\hline \multicolumn{9}{|l|}{ Use of central venous access } \\
\hline Up to 6 days & 114 & 63.0 & 16 & 14.0 & 1.00 & - & - & - \\
\hline 7 or more days & 67 & 37.0 & 18 & 26.9 & 1.91 & $1.04-3.50$ & - & - \\
\hline \multicolumn{9}{|l|}{ Use of mechanical ventilation } \\
\hline None & 104 & 57.4 & 4 & 3.9 & 1.00 & - & 1.00 & - \\
\hline 1 to 3 days & 30 & 16.6 & 10 & 33.3 & 8.67 & $2.92-25.75$ & 4.44 & $1.66-11.87$ \\
\hline 4 or more days & 47 & 26.0 & 20 & 42.6 & 11.06 & $3.99-30.67$ & 6.87 & $2.58-18.27$ \\
\hline
\end{tabular}

$\mathrm{RR}=$ relative risk; $\mathrm{C} 195 \%=95 \%$ confidence interval; * Advanced resuscitation $=$ positive pressure ventilation + cardiac massage and/or drugs; $\mathrm{CPAP}=$ continuous positive pressure $($ pressão positiva contínua). 
Table 3

Description on the clinical assessment of the studied population $(\mathrm{N}=181)$, incidence, and relative risk for the occurrence of deaths. Preterm Born Cohort, 2016 .

\begin{tabular}{|c|c|c|c|c|c|c|c|c|}
\hline \multirow[t]{2}{*}{ Variables } & \multirow[t]{2}{*}{$\mathbf{N}$} & \multirow[t]{2}{*}{$\%$} & \multicolumn{6}{|c|}{ Death } \\
\hline & & & $\mathrm{n}$ & $\%$ & $\mathrm{RR}_{\text {crude }}$ & $\mathrm{Cl} 95 \%$ & $\mathrm{RR}_{\text {Adjusted }}$ & $\mathrm{Cl} 95 \%$ \\
\hline \multicolumn{9}{|c|}{ Early sepsis } \\
\hline No & 50 & 27.6 & 4 & 8.0 & 1.00 & - & - & - \\
\hline Yes & 131 & 72.4 & 30 & 22.9 & 2.86 & $1.05-7.73$ & - & - \\
\hline \multicolumn{9}{|c|}{ Late sepsis } \\
\hline No & 117 & 64.6 & 8 & 6.8 & 1.00 & - & 1.00 & - \\
\hline Yes & 64 & 35.4 & 26 & 40.6 & 5.94 & $2.85-12.37$ & 3.72 & $1.77-7.83$ \\
\hline \multicolumn{9}{|c|}{ Acute Respiratory Distress Syndrome } \\
\hline No & 123 & 68.0 & 11 & 8.9 & 1.00 & - & 1.00 & - \\
\hline Yes & 58 & 32.0 & 23 & 39.7 & 4.43 & $2.31-8.48$ & 2.86 & $1.49-5.46$ \\
\hline \multicolumn{9}{|c|}{ Pulmonary hemorrhage } \\
\hline No & 179 & 98.9 & 32 & 17.9 & 1.00 & - & 1.00 & - \\
\hline Yes & 2 & 1.1 & 2 & 100.00 & 5.59 & $4.08-7.66$ & 1.97 & $1.40-2.77$ \\
\hline \multicolumn{9}{|c|}{ Necrotizing enterocolitis } \\
\hline No & 176 & 97.2 & 30 & 17.1 & 1.00 & - & 1.00 & - \\
\hline Yes & 5 & 2.8 & 4 & 80.0 & 4.69 & $2.71-8.11$ & 3.41 & $1.70-6.83$ \\
\hline
\end{tabular}

$R R=$ relative risk $; C \mid 95 \%=95 \%$ confidence interval 


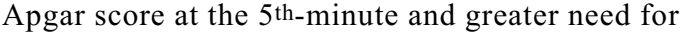
invasive mechanical ventilation. The following associated clinical conditions also interfered in the survival: late sepsis, necrotizing enterocolitis, acute respiratory distress syndrome, and pulmonary hemorrhage.

The difficulty of directly comparing our findings with other findings on preterm cohorts should be emphasized, mainly due to methodological differences employed, since some restrict the analysis to certain GA subgroups or weight. In this cohort, an analysis of all GA and birth weights was performed.

In this series, $59.1 \%$ of the preterm infants with a GA of $<28$ weeks died, a result observed in Sweden (22\%), Canada (14.7\%), and China (31\%).6,18,19 In Brazil, a research carried out in Viçosa, in the State of Minas Gerais, showed that $13.3 \%$ of the preterm infants died, and in the extreme preterm infant subgroup, this rate was $47.5 \% .5$ Conversely, a study conducted by the Rede Brasileira de Pesquisas Neonatais (Brazilian Network of Neonatal Research) with GA preterm infants from 23 to 33, weighting between 400 and $1,499 \mathrm{~g}$ and without congenital malformations represented $30 \%$ of deaths in hospital units; this rate was higher than found in our cohort, but with some methodological differences in relation to the eligible population. 7

In the aspect discussed above, regional and local inequalities related to obstetric and neonatal care of greater complexity cannot be disregarded in our country, where we verified the inadequate or insufficient incorporation of technologies, inputs, and human resources in several cities. ${ }^{4}$ In our region, many pregnant women at risk in the Public Health System (SUS) at the time of childbirth, do not have access to the reference maternity, and preterm infants are born in the surrounding towns. After this birth, preterm infants remain in the hospitals with few diagnostic and therapeutic interventions, dispute vacancies in the neonatal intensive care units and are subjected to risky neonatal transportation. These factors probably interfere with their prognosis.

Therefore, specific regional and local public policies should be reviewed to consolidate the Rede de Assistência Perinatal (Perinatal Care Network), with cost-effectiveness assessments, by secondary care expansion for high-risk pregnant women, beds at referred maternity, health education, greater availability of beds at the neonatal ICU, guarantee adequate inter-hospital transportation, and a creation of a systematic assessment database on the main quality of care indicators offered. 20 With the greater availability of dense technologies, the use of light technologies should be emphasized, in the command of the whole work process, employing sensitive listening to mothers and family members, respecting the singularities, skin-to-skin contact stimulation: mother and newborn after birth (if possible) and guaranteeing that the preterm infant receives breastmilk.

In this study, the Apgar score $<7$ at the 5 thminute increased the risk of death by $82 \%$, an association confirmed in other studies. 5,7,13,21 This score allows us to assess the newborns' vitality conditions after birth and perinatal asphyxia is considered when Apgar score $<7$ at the $5^{\text {th-minute, }}{ }^{11}$ which can cause avoidable death through appropriate, systematic, and uniform measures in childbirth and birth care to reduce fetal suffering and complications. 14,15

The highest number of days of invasive mechanical ventilation presented a dose-response relationship for the occurrence of the outcome. Its use during 1 to 3 days increased deaths risk by 4 times, whereas, its use for $\geq 4$ days increased by almost 7 times this risk, an association corroborated by other researchers. 6 A systematic review of invasive mechanical ventilation in preterm infants demonstrates other complications of this modality, such as pulmonary bronchodysplasia, pulmonary hemorrhage, and ventilator-associated pneumonia. 22 Such an invasive procedure is indicated for the most critical patients, and its appropriate use constitutes an impact on the reduction of deaths, being the primordial elaboration of well-defined clinical protocols at the beginning and the end of its use.

In this study, the diagnosis on late sepsis, respiratory distress syndrome, pulmonary hemorrhage, and necrotizing enterocolitis was strongly associated with death, and such findings were also found by other authors. 5,6,7,9 Late sepsis should be of great concern at the neonatal ICU due to its association with invasive procedures, often used in preterm infants. 23 These results demonstrate the need for improvements concerning the care provided at the neonatal ICU; therefore, permanent surveillance methods and preventive actions of healthcare-related infections (HRI) should be intensified through daily follow-ups of diagnosed infections, such as contamination sites and better integration between the care professional and hospital infection control commission (HICC). ${ }^{24}$

Acute respiratory distress syndrome (ARDS) was strongly associated with death during their hospitalization at the neonatal ICU, a finding also verified in other studies.7,9 The protective effect of antenatal corticosteroids can prevent and reduce ARDS severity, optimize the effect of surfactant 
therapy after birth, and reduce the incidence of periintraventricular hemorrhage. 25 We verified in this cohort that only $35.4 \%$ of the mothers were administered antenatal corticosteroids; however, these data were not found in $17.1 \%$ of the medical records (data not previously shown). Remarkably, one of the neonatal ICU located in a hospital that does not perform obstetric procedures, which limited the acquisition of this information.

In Brazil, differences in the use of antenatal corticosteroids greatly varied in studies, with variations ranging from 39.3 to $70.1 \% .5,9$ Therefore, we found controversial results: low-frequency antenatal corticosteroid use or no reference to its use in medical records. As recommended by the Ministry of Health, all pregnant women with GA between 24 and 34 weeks, with a risk of preterm childbirth, should be considered as candidates for antenatal treatment with corticosteroids, except those with contraindication. 26 Regarding to the late preterm ( $G A \geq 34$ and $<37$ weeks), the Society of Maternal Fetal Medicine and the American Academy of Gynecology and Obstetrics recommend the extension of antenatal corticosteroid use to this specific group in assessed clinical situations due to reduce short-term respiratory morbidities. 27 Therefore, these results justify the need to review clinical protocols for prenatal care. Regarding the main ARDS therapy with the exogenous surfactant, no significant difference was found with its use in relation to the outcome.

Necrotizing enterocolitis (NEC) is considered one of the most enigmatic and feared morbidities at the neonatal ICU.28 In this study, despite the low incidence of NEC (2.8\%), we observed concerning results: $80 \%$ of the preterm infants had an unfavorable outcome, and this clinical condition increased the risk of death by $240 \%(\mathrm{CI} 95 \%=1.70-6.83)$. A study conducted by the Vermont Oxford Network (VON), with 71,808 preterm infants, showed a mortality rate for NEC of $16-42 \%$, according to weight subdivisions. ${ }^{29}$ Remarkably, the results found were to emphasize the need for reviewing care protocols with better scientific evidence to prevent NEC, such as the use of antenatal corticosteroids (when indicated), use of breastmilk, avoid unnecessary antibiotics, standardize feeding protocols, and among others. ${ }^{30}$

Among the limitations in this study, we highlight a possible bias information due to the collection of medical records, containing difficulties in acquiring data related to maternal characteristics, pregnancy, and time of childbirth. For this reason, analyzing the preterm infants' health conditions and the neonatal care received were prioritized, with these data being more consistent and reliable.

During the study period, the evaluated units did not perform any severity score calculations, such as the Neonatal Therapeutic Intervention Scoring System (NTISS). Despite the possibility of estimating them retrospectively, some necessary information was not obtained from the medical records, making comparisons between the population's characteristics at different intensive care units and in the service itself, making it difficult over time.

Regarding to the non-located medical records, due to their physical nature and many of them of long permanence, making it difficult to store them in hospital units, but as for the outcome studied, the losses did not influence the results, as verified by the differential loss analysis.

This study is a pioneer in the region and it describes hospitalized preterm infants' characteristics, health conditions, and neonatal care effects of their death at the neonatal ICU. The results showed that the death rates were similar to those in national studies, but distinct from those observed in international studies. Deaths were associated with lower gestational age, Apgar score $<7$ at the 5 th-minute, a higher number of days of mechanical ventilation, diagnosis of late sepsis, respiratory distress syndrome, pulmonary hemorrhage, and necrotizing enterocolitis. These findings suggest the importance of using specific strategies to improve care for the preterm infant during birth, specific protocols to conduct extremely preterm, early weaning from invasive mechanical ventilation, and prevention of nosocomial infection.

\section{Authors' contribution}

Study conception and design: Lima RG, Vieira VC, and Medeiros DS. Study implementation and collection: Lima RG and Viera VC. Statistical analysis and interpretation: Lima RG and Medeiros DS. Drafting: Lima RG. Critical review: Vieira VC and Medeiros DS. All authors approved the final version of the article. 


\section{References}

1. WHO (World Health Organization). Born too soon: the global action report on preterm birth [online]. Geneva, Switzerland; 2012. [acesso 2 jun 2019]. 112: 9p. Disponível em: https://www.who.int/pmnch/media/news/2012/201204 borntoosoon-report.pdf.

2. UNICEF (United Nations Children's Fund). Levels \& trends in child mortality. Report 2017. Estimates developed by the UN Inter-agency Group for Child Mortality Estimation. [online]. New York, USA; 2017. [acesso 30 mai 2019]. 36: 11p. Disponível em: https://www.unicef.org/ publications/files/Child_Mortality_Report_2017.pdf.

3. França EB, Lansky S, Rego MAS, Malta DC, França JS, Teixeira R, Porto D, de Almeida MF, de Souza MFM, Szwarchwald CL, Mooney M, Naghavi M, Vascocelos AMN. Principais causas da mortalidade na infância no Brasil, em 1990 e 2015: estimativas do estudo de carga global de doença. Rev Bras Epidemiol . 2017; 20: 46-60.

4. Carlo WA, Travers CP. Maternal and neonatal mortality: time to act. J Pediatr. 2016; 92 (6): 543-5.

5. Freitas BAC, Sant"Ana LFR, Longo GZ, Siqueira-Batista R, Priore SE, Franceschini SCC. Características epidemiológicas e óbitos de prematuros atendidos em hospital de referência para gestante de alto risco. Rev Bras Ter Intensiva . 2012; 24 (4): 386-92.

6. Zhou WQ, Mei YB, Zhang XY, Li QP, Kong XY, Feng ZC. Neonatal outcomes of very preterm infants from a neonatal intensive care center. World J Clin Pediatr. 2014; 10 (1): 538 .

7. Guinsburg R, de Almeida MFB, de Castro JS, Silveira RC, Caldas JPdS, Fiori HH, do Vale MS, Abdallah VOS, Cardoso LEMB, Ferrari LSL, Bentlin MR, Venzon OS, Ferri WAG, Meneses JA, Diniz EMA, Zanaroli DMT, dos Santos CN, Duarte JLB, Rego MAS. Death or survival with major morbidity in VLBW infants born at Brazilian neonatal research network centers. J Matern-Fetal Neo M. 2015; 29 (6): 1005-9.

8. Eichenwald EC, Stark AR. Management and outcomes of very low birth weight. N Engl J Med. 2008; 358 (16): 170011.

9. Castro MP, Rugolo LMSS, Margotto PR. Sobrevida e morbidade em prematuros com menos de 32 semanas de gestação na região central do Brasil. Rev Bras Ginecol Obstet. 2012; 34 (5): 235-42

10. IBGE (Instituto Brasileiro de Geografia e Estatística). Portal da Transparência. 2020 [acesso 28 fev 2020]. Disponível em: https://ibge.gov.br/.

11. Carmo Leal M, Silva AAM, Dias MAB, da Gama SGN, Rattner D, Moreira ME, Filha MMT, Domingues RMSM, Pereira APE, Torres JA, Bittencourt ADA,D’Orsi E, Cunha AJLA, Leite AJM, Cavalcante RS, Lanky S, Diniz CSG, SzwarcwaldCL. Birth in Brazil: national survey into labour and birth. Reprod Health. 2012; 9 (1): 15

12. Brasil. Ministério da Saúde. Secretaria de Atenção à Saúde. Departamento de Ações Programáticas e Estratégicas. Atenção à Saúde do Recém-Nascido: guia para os profissionais de saúde. Brasília, DF; 2011. v.1. p.192.

13. Ballard J, Khoury J, Wedig K, Wang L, Eilers-Walsman B,
Lipp R. New Ballard Score, expanded to include extremely premature infants. J Pediatr. 1991; 119 (3): 417-23.

14. Guinsburg R, de Almeida MFB. Reanimação do prematuro $<34$ semanas em sala de parto: Diretrizes da Sociedade Brasileira de Pediatria [periódico online].2016 [acesso 2 jun 2019]. Disponível em: https://www.sbp.com.br/ fileadmin/user_upload/DiretrizesSBPReanimacaoPrematur oMenor 34semanas26jan2016.pdf.

15. Silva CF, Leite AJM, Almeida NMGS, Leon ACMP, Olofin I. Fatores associados ao óbito neonatal de recém-nascidos de alto risco: estudo multicêntrico em Unidades Neonatais de Alto Risco no Nordeste brasileiro. Cad Saúde Pública. 2014; 30 (2): 355-68.

16. Lansky S, Friche AAL, da Silva AAM, Campos D, Bittencourt SDA, de Carvalho ML, de Frias PG, Cavalcante RS, da Cunha AJLA. Pesquisa Nascer no Brasil: perfil da mortalidade neonatal e avaliação da assistência à gestante $\mathrm{e}$ ao recém-nascido. Cad Saúde Pública. 2014; 30: S192S207.

17. Szwarcwald CL,Damacena GN. Amostras complexas em inquéritos populacionais: planejamento e implicações na análise estatística dos dados. Rev Bras Epidemiol. 2008; 11: $38-45$.

18. Group E. Incidence of and risk factors for neonatal morbidity after active perinatal care: extremely preterm infants study in Sweden (EXPRESS). Acta Paediatr. 2010; 99 (7): 978-92.

19. Shah P, Sankaran K, Aziz K, Allen A, Seshia M, Ohlsson A, Lee SK. Outcomes of preterm infants $<29$ weeks gestation over 10-year period in Canada: a cause for concern? J Perinatol. 2012; 32 (2): 132.

20. Sociedade Brasileira de Pediatria. Nascimento Seguro. Documento científico do Departamento Científico de Neonatologia [periódico online]. 2018 [acesso 10 mai2019]; Disponível em: <http://www.sbp.com.br/ fileadmin/user_upload/Neonatologia_-_20880b-DC_Nascimento_seguro_003_pdf>.

21. Ghorbani F, Heidarzadeh M, Dastgiri S, Ghazi M, Rahkar Farshi M. Survival of Premature and Low Birth Weight Infants: A Multicenter, Prospective, Cohort Study in Iran. Iranian J Neonatol. 2017; 8 (1): 16-22.

22. Guedes JM, Conceição SL, dos Santos Albergaria TF. Efeitos deletérios da ventilação mecânica invasiva em prematuros: revisão sistemática. Rev Pesq Fisioter. 2018; 8 (1): 119-30.

23. Freitas BAC, Peloso M, Manella LD, Franceschini SCC, Longo GZ, Gomes AP, Batista- Siqueira R. Sepse tardia em pré-termos de uma unidade de terapia intensiva neonatal: análise de três anos. Rev Bras Ter Intensiva. 2012; 24 (1): $79-85$.

24. Brasil. Ministério da Saúde. Gerência de Vigilância e Monitoramento em Serviços de Saúde (GVIMS). Gerência Geral e Tecnologia em Serviços de Saúde (GGTES). Critérios Diagnósticos de Infecção Associada à Assistência à Saúde-Neonatologia. Brasília, DF; 2014. v. 3. p. 65.

25. Gilstrap LC, Christensen R, Clewell WH, D'Alton ME, Davidson EC, EscobedoMB,Gjerdingen DK, Goddard- 
Finegold JG, Goldenberg RL, Grimes DA, Hansen TN, Kauffman RE, Keeler EB, Oh W, Susman EJ, Vogel MG, Avery ME, Ballard PL, Ballard RA, Crowley P, Garite T, Hankins GDV, Jobe AH, Koppe JG, Maher JE, Merkatz IR, Shankaran S, Simpson KN, Sinclair JC, Slotkin TA, Taeusch Jr W, Wright LL, Alexander D, Berberich MA, Bracken M, Cooper L, Culpepper L, Elliott JM, Ferguson JH, Frigoletto F, Gail DB, Hall WH, Jones Jr D, MedoffCooper B, Merenstein GB, Whalen JM, Lenfant C, Hinshaw AS. Effect of corticosteroids for fetal maturation on perinatal outcomes: NIH consensus development panel on the effect of corticosteroids for fetal maturation on perinatal outcomes. JAMA. 1995; 273 (5): 413-8.

26. Brasil. Ministério da Saúde. Secretaria de Atenção à saúde. Departamento de Ações Programáticas e Estratégicas. Gestação de alto risco: manual técnico. Brasília, DF; 2012. 5 ed. p. 302

27. Bannerman CG, Thom EA, Blackwell SC, Tita ATN, Reddy UM, Saade GR, Rouse DJ, McKenna DS, Clark EAS, Thorp Jr JM, Chien EK, Peaceman AM, Gibbs RS, Swamy GK, Norton ME, Casey BM, Caritis SN, Tolosa JE, Sorokin Y, VanDorsten JP, Jain L. Antenatal Corticosteroids for Womenat Risk of Late Preterm Delivery. N Engl J Med. 2016; 374 (14): 1311-20

Received on September 6, 2019

Final version presented on March 13, 2020

Approved on April 14, 2020
28. Ortigoza BE, Neu J. Enterocolite necrosante. In: Polin RA, Yonder MC. Neonatologia Prática. 5 ed. Rio de Janeiro: Elsevier; 2016. p. 448-60.

29. Fitzgibbons SC, Ching Y, Yu D, Carpenter J, Kenny M, Weldon C, Lillehei C, Valin C, Horbar JD, Jaksic T. Mortality of necrotizing enterocolitis expressed by birth weight categories. J Pediatr Surg. 2009; 44 (6): 1072-6.

30. Patel AL, Panagos PG, Silvestri JM. Reducing incidence of necrotizing enterocolitis. Clin Perinatol. 2017; 44 (3): 683700 . 